\title{
On the heating environment in street canyon
}

\author{
Rizwan Ahmed Memon • D. Y. C. Leung
}

Received: 7 April 2010 / Accepted: 7 December 2010 / Published online: 28 December 2010

(C) The Author(s) 2010. This article is published with open access at Springerlink.com

\begin{abstract}
This study investigates the impact of building aspect ratio (building-height-tostreet-canyon-width-ratio), wind speed and surface and air-temperature difference $\left(\Delta \theta_{\mathrm{s}-\mathrm{a}}\right)$ on the heating environment within street canyon. The Reynolds-averaged Navier-Stokes (RANS) and energy transport equations were solved with Renormalization group (RNG) theory version of $\mathrm{k}-\varepsilon$ turbulence model. The validation process demonstrated that the model could be trusted for simulating air-temperature and velocity trends. The temperature and velocity patterns were discussed in idealized street canyons of different aspect ratios $(0.5-$ $2.0)$ with varying ambient wind speeds $(0.5-1.5 \mathrm{~m} / \mathrm{s})$ and $\Delta \theta_{\mathrm{s}-\mathrm{a}}(2-8 \mathrm{~K})$. Results show that air-temperatures are directly proportional to bulk Richardson number $\left(R_{b}\right)$ for all but ground heating situation. Conversely, air-temperatures increase significantly across the street canyon with a decrease in ambient wind speed; however, the impact of $\Delta \theta_{\mathrm{s}-\mathrm{a}}$ was negligible. Clearly, ambient wind speed decreases significantly as it passes over higher AR street canyons. Notably, air-temperatures were the highest when the windward wall was heated and the least during ground heating. Conversely, air-temperatures were lower along the windward side but higher within the street canyon when the windward wall was heated.
\end{abstract}

Keywords Heating $\cdot$ Surface-temperature $\cdot$ CFD $\cdot$ Turbulence $\cdot$ Street-canyon

R. A. Memon $(\bowtie)$

Department of Mechanical Engineering, Mehran University of Engineering \& Technology, Jamshoro, Sindh, Pakistan

e-mail: rizwanhashmani@yahoo.com

D. Y. C. Leung

Department of Mechanical Engineering, University of Hong Kong,

Pokfulam Road, Pokfulam, Hong Kong 


\section{List of symbols}

AR Aspect ratio

$\mathrm{H} \quad$ Street canyon height $(\mathrm{m})$

W Street canyon width $(\mathrm{m})$

$\mathrm{X} / \mathrm{W}$ Spatial co-ordinate in X-direction non-dimensionalised by street canyon width

$\bar{u}_{i} \quad$ Mean streamwise $(u)$ and vertical $(v)$ velocity components $\left(\mathrm{ms}^{-1}\right)$

$u_{a} \quad$ Horizontal inflow wind speed $\left(\mathrm{ms}^{-1}\right)$

$\varepsilon \quad$ Dissipation rate of turbulent kinetic energy $\left(\mathrm{m}^{2} \mathrm{~s}^{-3}\right)$

$\theta_{g} \quad$ Ground level temperature (K)

$\mu_{\text {eff }} \quad$ Effective turbulent viscosity

$G_{b} \quad$ Turbulence kinetic energy production due to buoyancy $\left(\mathrm{kgm}^{-1} \mathrm{~s}^{-3}\right)$

$\operatorname{Pr}_{t} \quad$ Turbulent Prandtl number

$v \quad$ Kinematic viscosity $\left(\mu_{e f f} / \rho\right)\left(\mathrm{m}^{2} \mathrm{~s}^{-1}\right)$

$\overline{u_{i}^{\prime} u_{j}^{\prime}} \quad$ Reynolds stresses $\left(\mathrm{m}^{2} \mathrm{~s}^{-2}\right)$

$\mathrm{Re}_{y} \quad$ Wall distance based Reynolds number

$g \quad$ Acceleration due to gravity $\left(\mathrm{ms}^{-2}\right)$

$p \quad$ Pressure (Pascal)

$u_{i} \quad$ Velocity components $(\mathrm{u}, \mathrm{v})$ in the $\mathrm{x}$ and $\mathrm{z}$ directions $\left(\mathrm{ms}^{-1}\right)$

$\mathrm{Z} / \mathrm{H} \quad$ Spatial coordinate in $\mathrm{Z}$ direction non-dimensionalized by street canyon height

$\operatorname{Re}_{H} \quad$ Reynolds number (based on street canyon height) $=\mathrm{u}_{\mathrm{a}} \mathrm{H} / \mathrm{v}$

$\mathrm{R}_{b} \quad$ Bulk Richardson number $=\frac{g H\left(\theta_{a}-\theta_{g}\right)}{\theta_{a} u_{a}^{2}}$

$k \quad$ Turbulent kinetic energy $\left(\mathrm{m}^{2} \mathrm{~s}^{-2}\right)$

$\theta_{a} \quad$ Ambient air-temperature (K)

$\mu_{t} \quad$ Turbulent viscosity

$G_{k} \quad$ Turbulence kinetic energy production due to mean velocity gradient $\left(\mathrm{kgm}^{-1} \mathrm{~s}^{-3}\right)$

$\beta \quad$ Thermal expansion coefficient $(\mathrm{K})$

$S_{i j} \quad$ Mean rate of strain tensor (1/s)

$\alpha_{k}, \alpha_{\varepsilon}$ Inverse Prandtl number for $\mathrm{k}$ and $\varepsilon$

$\Delta \theta_{\mathrm{s}-\mathrm{a}} \quad$ Difference between the surface and ambient air-temperature (K)

\section{Introduction}

Global warming is perhaps the most widely reported and acknowledged consequent of anthropogenic activities. The urban cities and localities that are the epic center of most anthropogenic activities have been severely affected by the deteriorated heating environment [1-3]. However, heating in an area could be a mutual response of many meteorological (e.g., wind speed) and manmade (e.g., street canyon geometry) factors [4-6] and could be avoided or alleviated with suitable design of urban areas. Although urban heating and related problems have been studied extensively through numerical modeling [2,7-14], studying the impact of urban design or meteorological parameters on heating is limited $[15,16]$. On the other hand, computational fluid dynamics (CFD) technique has widely been applied on studying fluid flow and pollutant dispersion especially in street canyons [17-21]. Subsequently, CFD studies have adopted the $\mathrm{k}-\varepsilon$ model in solving various street canyon heating situations [22-26]. Moreover, it is reported that the RNG version of $\mathrm{k}-\varepsilon$ turbulence model is better in solving the heating environment within and above street canyons. In a study conducted by Xie et al. [26], the RNG version of k- $\varepsilon$ turbulence model was used to solve the steady-state Navier Stokes and energy transport equations when different street canyon surfaces were heated. 
Another study found that the RNG version of $\mathrm{k}-\varepsilon$ turbulence model was the optimum for studying dispersion in an isolated street canyon [27]. In a recent study, Memon et al. [6] have also used the RNG version to investigate the trends of heating within street canyon. However, that study did not discuss the combined impact of AR and $\Delta \theta_{\mathrm{s}-\mathrm{a}}$ on ambient wind speed and the temperature and velocity trends during different situations were not elaborated sufficiently. Additionally, Memon et al. [6] have used a coarse mesh and the effects of $\Delta \theta_{s-a}$ on heating within street canyon were not included. The present study is an extension to our previous published work as the aforementioned gaps have been filled while a fine mesh is used. However, new cases are simulated for this paper to enhance our understanding on the phenomenon. The computational domain for three ARs (i.e., 0.5, 1 and 2) is simulated with varying ambient wind speeds (i.e., $0.5-1.5 \mathrm{~m} / \mathrm{s}$ ) that results in a Reynolds number ranging from around 16,600 (i.e., $A R=0.5$, wind speed $=0.5 \mathrm{~m} / \mathrm{s}$ ) to around 200,000 (i.e., $\mathrm{AR}=2$, wind speed $=1.5 \mathrm{~m} / \mathrm{s}$ ). The $\Delta \theta_{\mathrm{s}-\mathrm{a}}$ varied from 2 to $8 \mathrm{~K}$ which results in a bulk Richardson number $\left(\mathrm{R}_{\mathrm{b}}\right)$ from around -0.01 (i.e., $\mathrm{AR}=0.5$, wind speed $=0.5 \mathrm{~m} / \mathrm{s}, \Delta \theta_{\mathrm{s}-\mathrm{a}}=2 \mathrm{~K}$ ) to around -2.14 (i.e., $\mathrm{AR}=2$, wind speed $=0.5 \mathrm{~m} / \mathrm{s}, \Delta \theta_{\mathrm{s}-\mathrm{a}}=8 \mathrm{~K}$ ).

\section{Numerical model}

The governing equations for this study are based on the principles of conservation of mass (Continuity equation), momentum and energy (Eqs. 1-3). Consequently, equations for turbulent kinetic energy $(\mathrm{k})$ and turbulent dissipation rate $(\varepsilon)($ Eqs. 4,5$)$ are also solved, as given by the RNG theory [28], to address the closure problem.

$$
\begin{gathered}
\frac{\partial \bar{u}_{i}}{\partial x_{i}}=0 \\
\bar{u}_{i} \frac{\partial \bar{\theta}}{\partial x_{i}}+\frac{\partial\left(\overline{u_{i}^{\prime} \theta^{\prime}}\right)}{\partial x_{i}}=0 \\
\bar{u}_{j} \frac{\partial \bar{u}_{i}}{\partial x_{j}}=-\frac{1}{\rho} \frac{\partial \bar{p}}{\partial x_{i}}+v \frac{\partial^{2} \bar{u}_{i}}{\partial x_{j}^{2}}-\frac{\partial}{\partial x_{j}} \overline{\left(u_{i}^{\prime} u_{j}^{\prime}\right)}+\left(\frac{\rho-\rho_{o}}{\rho}\right) g_{i} \\
\bar{u}_{i} \frac{\partial k}{\partial x_{i}}=\frac{1}{\rho} \frac{\partial}{\partial x_{i}}\left(\alpha_{k} \mu_{e f f} \frac{\partial k}{\partial x_{i}}\right)+\frac{G_{b}}{\rho}+\frac{G_{k}}{\rho}-\varepsilon \\
\frac{\partial \varepsilon}{\partial x_{i}}=\frac{1}{\rho} \frac{\partial}{\partial x_{i}}\left(\alpha_{\varepsilon} \mu_{e f f} \frac{\partial \varepsilon}{\partial x_{i}}\right)+\frac{1}{\rho} C_{\varepsilon 1} \frac{\varepsilon}{k}\left(G_{k}+C_{\varepsilon 3} G_{b}\right) \\
-\left[C_{\varepsilon 2}+\frac{C_{\mu} \rho \eta^{3}\left(1-\eta / \eta_{o}\right)}{1+\beta \eta^{3}}\right] \frac{\varepsilon^{2}}{k}
\end{gathered}
$$

where,

$$
\begin{aligned}
G_{b} & =\beta g \frac{\mu_{t}}{\operatorname{Pr}_{t}} \frac{\partial \bar{\theta}}{\partial x_{i}} \\
G_{k} & =\mu_{t} S^{2} \\
S & =\sqrt{2 S_{i j} S_{i j}} \\
\eta & =S k / \varepsilon
\end{aligned}
$$




$$
\begin{aligned}
S_{i j} & =\frac{1}{2}\left(\frac{\partial u_{j}}{\partial x_{i}}+\frac{\partial u_{i}}{\partial x_{j}}\right) \\
\beta & =-\frac{1}{\rho}\left(\frac{\partial \rho}{\partial \theta}\right)_{p} \\
\mu_{t} & =\rho C_{\mu} \frac{k^{2}}{\varepsilon}
\end{aligned}
$$

To solve the near wall flow, enhanced wall treatment is employed that needs finer mesh adjacent to the wall [29]. The mesh was, therefore, refined near the wall in the FLUENT model. The enhanced wall treatment uses the following formulation for effective turbulent viscosity $\left(\mu_{\text {eff }}\right)$ which is required in the $\mathrm{k}$ and $\varepsilon$ equations [30].

$$
\mu_{e f f}=\lambda_{\varepsilon} \mu_{t}+\left(1-\lambda_{\varepsilon}\right) \mu_{t, 2-\text { layer }}
$$

where,

$$
\begin{aligned}
\lambda_{\varepsilon} & =\frac{1}{2}\left[1+\tanh \left(\frac{\operatorname{Re}_{y}-\mathrm{Re}_{y}^{*}}{A}\right)\right] \\
A & =\left|\frac{\Delta \operatorname{Re}_{y}}{\tanh (0.98)}\right| \\
\operatorname{Re}_{y} & =\frac{\rho y \sqrt{k}}{\mu}
\end{aligned}
$$

The turbulent viscosity $\left(\mu_{t}\right)$ in Eq. 6 is evaluated from fully developed turbulent region $\left(\operatorname{Re}_{y}>\operatorname{Re}_{y}^{*}\right)$ where ' $y$ ' is the normal distance from the wall to the cell center and $\mu_{t, 2-l a y e r}$ is the two-layer formulation for turbulent viscosity in near wall viscosity affected region [29]. The following one equation model is integrated in Eq. 6 to solve the two-layer formulation [31].

$$
\mu_{t, 2-\text { layer }}=\rho C_{\mu} l_{\mu} \sqrt{k}
$$

where the length scale in the above equation is calculated as,

$$
l_{\mu}=y c_{l}\left(1-e^{-\operatorname{Re}_{y} / A_{\mu}}\right)
$$

The value for blending function (i.e., $\lambda \varepsilon$ ) reaches 1.0 in the fully developed turbulent region and becomes 0 in the near wall viscous region. In this regard, Fluent controls $\Delta \operatorname{Re}_{y}$ and assigns it a value equal to $5-20 \%$ of $\mathrm{Re}_{\mathrm{y}}$. The values for the constants used in the above model are given in Table 1. The variation in air density due to temperature change has been addressed by employing Boussinesq approximation. The effects of buoyancy have been addressed by introducing the last term on the right hand side of momentum equation (Eq. 3). The model consists of seven street canyons with the ambient air flow from the left and the top of the domain was kept at $3 \mathrm{H}$. The middle canyon has been considered as the target street canyon and all the results discussed hereafter are obtained from that street canyon. Details

Table 1 Empirical constants used to solve the model equations

\begin{tabular}{llllllllllll}
\hline $\mathrm{C}_{\varepsilon 1}$ & $\mathrm{C}_{\varepsilon 2}$ & $\mathrm{C}_{\varepsilon 3}$ & $\mathrm{Pr}_{t}$ & $\mathrm{C}_{\mu}$ & $\eta_{\mathrm{o}}$ & $\beta$ & $\mathrm{Re}_{y}^{*}$ & $\mathrm{~A}_{\mu}$ & $\alpha_{\mathrm{o}}$ & $\kappa$ & $\mathrm{C}_{1}$ \\
\hline 1.42 & 1.68 & $\tanh |v / u|$ & $1 / \alpha$ & 0.0845 & 4.38 & 0.012 & 200 & 70 & 1.0 & 0.419 & $\kappa C_{\mu}^{-3 / 4}$ \\
\hline
\end{tabular}


Table 2 Number of elements and face area in the three building aspect ratios

\begin{tabular}{lll}
\hline Street canyon AR & No. of elements & Face area \\
\hline 0.5 & $4,57,496$ & $6.25 \times 10^{-4} \mathrm{~m}^{2}$ \\
1.0 & $7,80,496$ & $6.25 \times 10^{-4} \mathrm{~m}^{2}$ \\
2.0 & $14,26,496$ & $6.25 \times 10^{-4} \mathrm{~m}^{2}$ \\
\hline
\end{tabular}

Symmetry Boundary

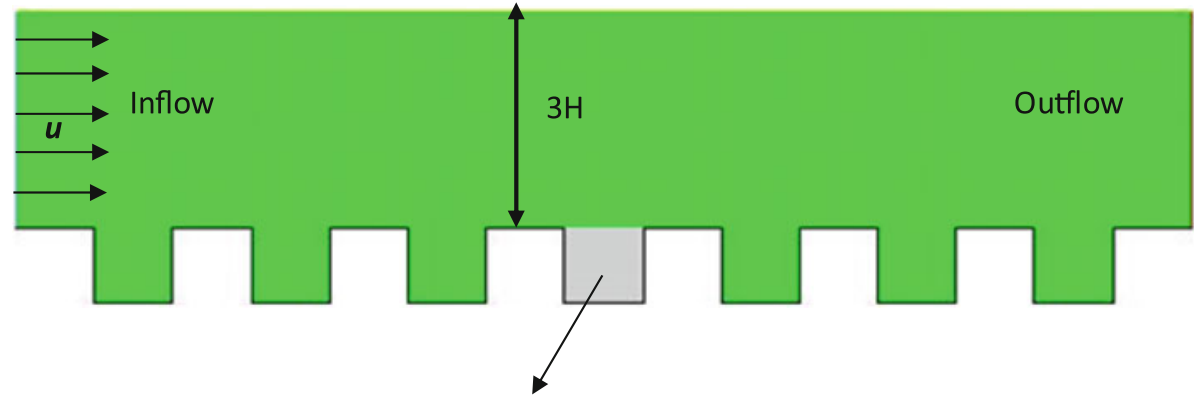

Target street canyon

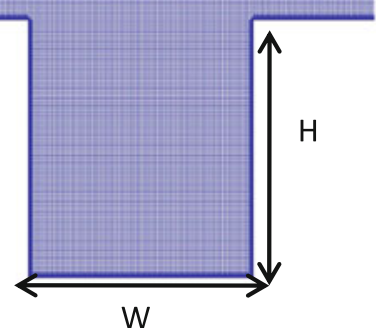

Fig. 1 Schematic diagram of computational domain with boundary conditions

of the number of elements for different ARs, boundary conditions and target street canyon are shown in Table 2 and Fig. 1.

\section{Model validation}

The street-canyon model adopted in this study is validated by comparing its results for potential temperature and horizontal velocity with the data obtained from a wind tunnel experiment [32]. Additionally, the results are also compared with those obtained from two numerical studies which had used similar type of model [23-25]. The potential temperature curve shows that temperature is low in the lower part of the street canyon, increased gradually up to a certain limit $(\mathrm{Z} / \mathrm{H} \leq 0.2)$, remained constant within the remaining part of canyon, increased near and slightly above the roof level and is constant aloft the canyon (Fig. 2). Evidently, deviations for the model are larger in the lower part of the canyon $(\mathrm{Z} / \mathrm{H}<0.7)$ only. However, the differences were observed both in the lower part $(\mathrm{Z} / \mathrm{H}<0.3)$ and from the middle up-to the roof level ( $\mathrm{Z} / \mathrm{H} \sim 0.4-1.0$ ) of the canyon when a coarse mesh was used [6]. Evidently, the velocity curve shows that the velocity is negative near the ground but increased within the canyon up-to slightly above roof level. The negative horizontal velocity near the ground might have been caused by a clockwise vortex in the street canyon [33]. Although the 


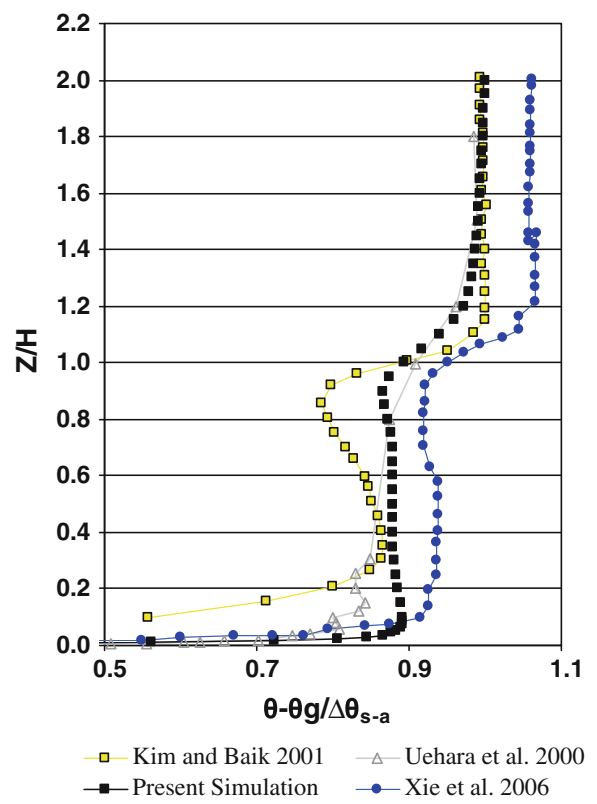

(a)

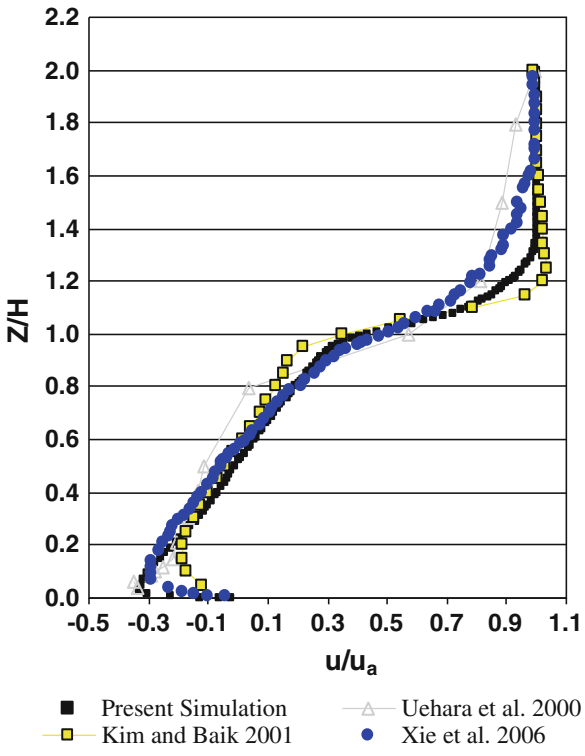

(b)

Fig. 2 A comparison of horizontal velocity and potential temperature. a Potential temperature. b Horizontal velocity

velocity curve of this study has mostly followed the similar curves for wind tunnel experiment and referred numerical studies, within the street canyon, deviations aloft $(\mathrm{Z} / \mathrm{H}>1.0)$ are comparatively larger. The mean differences at the position of deviation from wind tunnel data are given in Table 3. Notably, the horizontal velocity difference, above the canyon $(\mathrm{Z} / \mathrm{H}>1)$, of this model and the one adopted by Xie et al. [25] as compared to that of wind tunnel experiment is around -0.09 and -0.03 , respectively. Conclusively, the validation shows that the general trends of the wind tunnel experiment have been captured. However, the differences in the simulation results of this study, the referred numerical model studies and wind tunnel experiment could be a consequence of the differences in the simulation conditions and experimental set-up. In the all aforementioned cases, the results for normalized potential temperature and horizontal velocity are obtained for AR1 with a $R_{b}$ of -0.27 . However, the wind tunnel experiment data was obtained at $a R_{b}$ of -0.21 while both numerical studies have obtained their data $a t R_{b}$ of -0.27 . Notably, the wind tunnel experiment, present study and the referred numerical studies have all used a $\Delta \theta_{\mathrm{s}-\mathrm{a}}$ of $2 \mathrm{~K}$. The normalized potential temperature and horizontal velocity are obtained from the middle (target) street canyon i.e., the fourth canyon in this study. Conversely, Uehara [32] obtained all readings between the fifth and sixth rows of the model building blocks while Xie et al. [25] acquired their data from the fifth canyon. However, the data used by Uehara [32], Kim and Baik [23], Xie et al. [25] and this study have all been obtained at the central location of the domain. Conversely, Xie et al. [25] developed a two-dimensional computational domain with nine street canyons and unstructured grid. The computational domain developed for this study is also two-dimensional with seven street canyons and structured grid. Kim and Baik [23] have also used a two-dimensional computational domain with a single canyon and varying ambient windspeed. On the other hand, the model cubes were arranged in three-dimensional set-up in wind 
Table 3 Maximum deviations in potential temperature and horizontal velocity

\begin{tabular}{lllll}
\hline Normalized quantity & Z/H & Present simulation & Kim and Baik [23] & Xie et al. [25,26] \\
\hline$\left(\theta-\theta_{g}\right) / \Delta \theta_{\mathrm{s}-\mathrm{a}}$ & $0.05-0.7$ & -0.06 & +0.03 & -0.02 \\
$\left(u / u_{a}\right)$ & $1.0-1.8$ & -0.09 & -0.17 & -0.03 \\
\hline
\end{tabular}

The differences are calculated by subtracting the mean value of potential temperature and horizontal velocity of this model and the selected numerical models from that of the wind tunnel experiment [32]

tunnel experiment. Additionally, the wind tunnel experiment contained roughness elements that were not included in this or the two referred simulation studies. Conclusively, there are differences in the simulation models and wind tunnel experiment and the data obtained from them; however, overall comparison shows that the present model can be used for simulating temperature and wind profiles to a good reason of accuracy.

\section{Boundary conditions}

Notably, simulations in our published paper [6] were carried out on a coarse mesh model, with a higher surface and temperature difference $\left(\Delta \theta_{\mathrm{s}-\mathrm{a}}=16 \mathrm{~K}\right)$. On the other hand, simulations in this paper are carried out with a fine mesh with maximum surface and temperature difference of only $8 \mathrm{~K}$. It was shown that a street canyon can be heated in four different ways during a diurnal cycle [6]. The four situations were termed as night-time or uniformsurface heating, direct ground heating, leeward wall heating, and windward wall heating. In this study, the uniform-surface heating situation is simulated with three different values of $\Delta \theta_{\mathrm{s}-\mathrm{a}}$ for all the surfaces of street canyon (i.e., 2,4 and $8 \mathrm{~K}$ ). The ground heating is defined with a higher $\Delta \theta_{\mathrm{s}-\mathrm{a}}$ for ground (i.e., 4 and $8 \mathrm{~K}$ ) but lower and equal $\Delta \theta_{\mathrm{s}-\mathrm{a}}$ (i.e., $2 \mathrm{~K}$ ) for walls while the windward and leeward wall heating situations are simulated by defining a higher $\Delta \theta_{\mathrm{s}-\mathrm{a}}$ for windward/leeward wall (i.e., 4 and $8 \mathrm{~K}$ ) while the other wall was kept at a lower temperature (i.e., $\Delta \theta_{\mathrm{s}-\mathrm{a}}=2 \mathrm{~K}$ ). All walls were defined with fixed temperatures and no slip boundary condition. The ambient air entered into the street normal to the boundary from left side with a constant temperature and velocity magnitude. The turbulence has been specified with $\mathrm{k}$ and $\varepsilon$ turbulence method in fluent that introduces turbulence intensity with the equation, $\mathrm{I}=0.16\left(\mathrm{Re}_{\mathrm{H}}\right)^{-1 / 8}[29]$.

\section{Results}

A standard case (i.e., $\mathrm{AR}=1$, ambient wind speed $=1.5 \mathrm{~m} / \mathrm{s}$ and $\Delta \theta_{\mathrm{s}-\mathrm{a}}=8 \mathrm{~K}$ ) is selected with $a R_{b}$ of -0.12 to simulate extreme possible parameters. The standard case is simulated with different values of $\mathrm{AR}$ (i.e., 0.5 or $\mathrm{R}_{b}=-0.06$ and 2.0 or $\mathrm{R}_{b}=-0.24$ ), wind speed (i.e., $0.5 \mathrm{~m} / \mathrm{s}$ or $\mathrm{R}_{b}=-1.07,0.75 \mathrm{~m} / \mathrm{s}$ or $\mathrm{R}_{b}=0.48$ and $1 \mathrm{~m} / \mathrm{s}$ or $\mathrm{R}_{b}=-0.27$ ) and $\Delta \theta_{\mathrm{s}-\mathrm{a}}$ (i.e., $2 \mathrm{~K}$ or $\mathrm{R}_{b}=-0.07$ and $4 \mathrm{~K}$ or $\mathrm{R}_{b}=-0.13$ ) to assess the impact of different factors. The average air-temperature (whole-canyon-area-weighted) for the target street canyon is normalized for different street-canyon heating situations as shown in Fig. 3. Evidently, there has been an overall increase in air-temperature when $R_{b}$ is increased due to an increase in $A R$ in all but ground heating situation. Conversely, air-temperature increased with a decrease in ambient wind speed during all situations. 


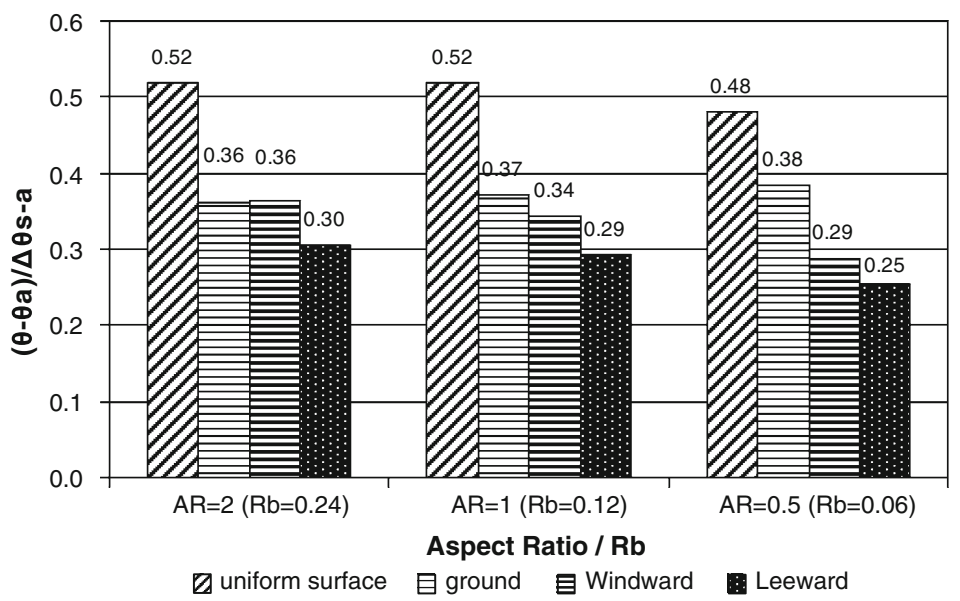

(a)

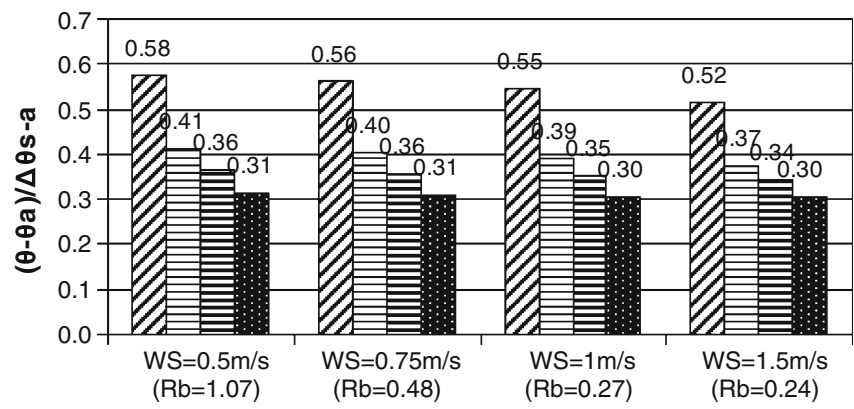

Wind speed / Rb

$\square$ uniform-surface

目ground 目 Windward

(b)

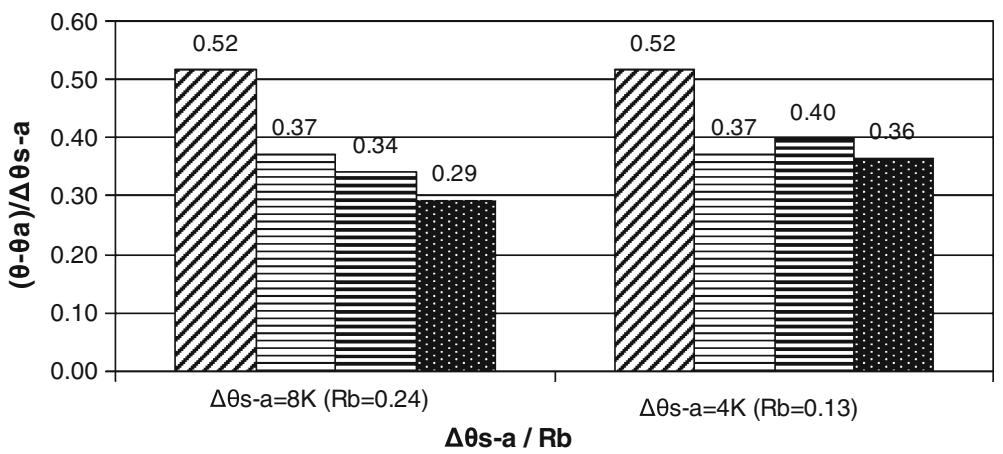

$\square$ uniform-surface

目 ground 目 Windward

Leeward

(c)

Fig. 3 Average (whole-canyon-area-weighted) normalized air-temperature during different heating situations. a Aspect ratio. b Wind speed. c $\Delta \theta_{\mathrm{s}-\mathrm{a}}$ 
Table 4 Linear regression correlations of average air-temperature (whole-canyon-area-weighted) with AR and wind speed

\begin{tabular}{|c|c|c|}
\hline Heating situation & Regression equation & $R^{2}$ \\
\hline \multirow{2}{*}{ Uniform-surface heating } & Tmp. $(\mathrm{K})=+0.20 * \mathrm{AR}+296.8$ & 0.62 \\
\hline & Tmp. $(\mathrm{K})=-0.46 * \mathrm{WS}+297.8$ & 0.99 \\
\hline \multirow{2}{*}{ Ground-heating } & Tmp. $(\mathrm{K})=-0.12 * \mathrm{AR}+296.0$ & 0.93 \\
\hline & Tmp. $(\mathrm{K})=-0.31 * \mathrm{WS}+296.4$ & 0.99 \\
\hline \multirow[t]{2}{*}{ Windward-wall heating } & $\operatorname{Tmp} .(\mathrm{K})=+0.37 * \mathrm{AR}+295.0$ & 0.80 \\
\hline & Tmp. $(\mathrm{K})=-0.17 * \mathrm{WS}+296.0$ & 0.99 \\
\hline \multirow[t]{2}{*}{ Leeward-wall heating } & $\operatorname{Tmp} .(\mathrm{K})=+0.25 * \mathrm{AR}+294.9$ & 0.78 \\
\hline & Tmp. $(\mathrm{K})=-0.06 * \mathrm{WS}+295.5$ & 0.74 \\
\hline
\end{tabular}

$A R$ Aspect ratio, WS Wind speed

Notably, air-temperature is higher in high aspect ratio street canyon in all but ground heating situation [6]. However, the highest average (whole-canyon-area-weighted) temperature difference is around $0.6 \mathrm{~K}(0.2 \%)$ between AR2 and AR 0.5 when $\Delta \theta_{\mathrm{s}-\mathrm{a}}$ is $8 \mathrm{~K}$ during windward wall heating. On the other hand, Memon et al. [6] reported that the highest temperature difference between ARs (AR8 and AR0.5) was observed during uniform-surface heating with higher $\Delta \theta_{\mathrm{s}-\mathrm{a}}(16 \mathrm{~K})$. Conversely, the average (whole-canyon-area-weighted) temperature in AR2 is around $0.2 \mathrm{~K}$ or $0.06 \%$ lower than that in AR0.5 during ground heating. A comparison of air-temperature and ambient wind speed indicates a negative correlation between them in all scenarios. The highest decrease in air-temperature is around $0.5 \mathrm{~K}$ (i.e., $0.16 \%$ ) when ambient wind speed $\left(u_{a}\right)$ is increased from 0.5 to $1.5 \mathrm{~m} / \mathrm{s}$ during uniform-surface heating. Linear regression of average (whole-canyon-area-weighted) air temperature with aspect ratio and ambient wind speed indicates strong correlations between them (Table 4). The regression equations show that an increase of AR by 0.5 will change the street canyon temperature by $+0.1,-0.05,+0.2$ and $+0.12 \mathrm{~K}$ during uniform surface, ground, windward wall and leeward wall heating situations, respectively. Conversely, an increase of $0.5 \mathrm{~m} / \mathrm{s}$ in the ambient wind speed would decrease the average street canyon temperature by $0.23,0.15,0.08$ and $0.03 \mathrm{~K}$ during uniform surface, ground, windward wall and leeward wall heating situations, respectively. The impact of $\Delta \theta_{\mathrm{s}-\mathrm{a}}$ seem to be marginal as the only notable change is observed during leeward wall heating as average air-temperature decreases by $0.07 \mathrm{~K}$ when $\Delta \theta_{\mathrm{s}-\mathrm{a}}$ increased from 4 to $8 \mathrm{~K}$.

\section{Discussion}

Spatial isotherms (Fig. 4), contours for turbulence intensity (Fig. 5) and figures depicting average temperature and/or velocity in different situations (Figs. 6, 7,8) are shown to discuss the above results in detail.

\subsection{Even heating of surfaces}

Figure 4a shows that temperature in the street canyon is the highest adjacent to the corners of the canyon and with the upper portion of the leeward wall. Conversely, temperature is lower at the centre of the canyon although a contour of higher temperature is evident near the ground. Seemingly, the fresh strong inflow of wind from the windward side of the street canyon results in significant temperature reductions along the windward wall. However, the 


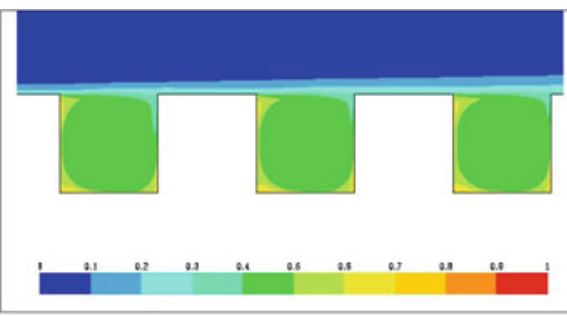

(a)

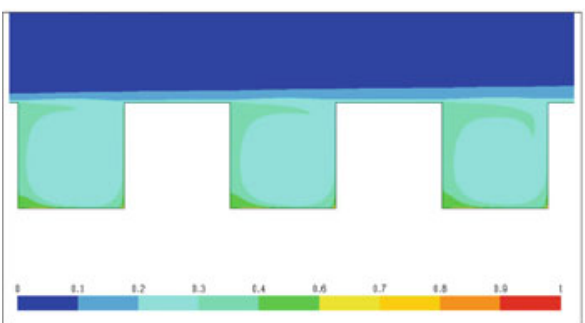

(b)

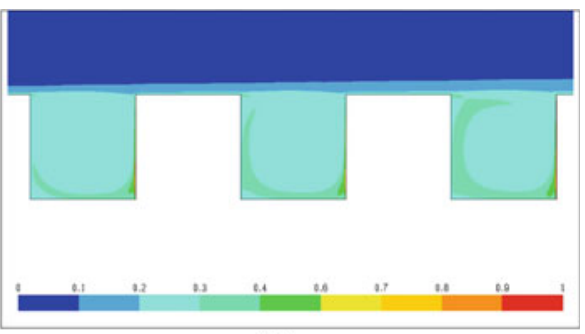

(c)

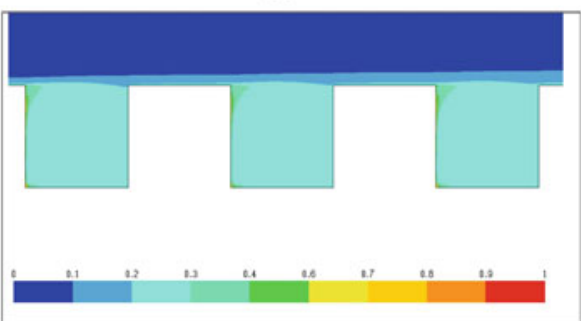

(d)

Fig. 4 Spatial isotherms for the standard case of different heating situations. a Even heating of surfaces. b Ground-heating. c Windward-wall heating. d Leeward wall heating

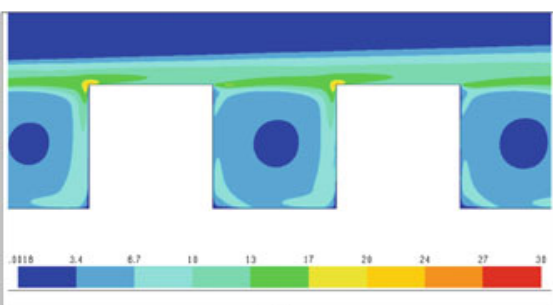

(a)

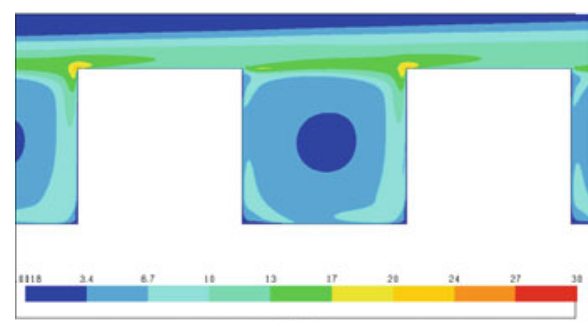

(b)

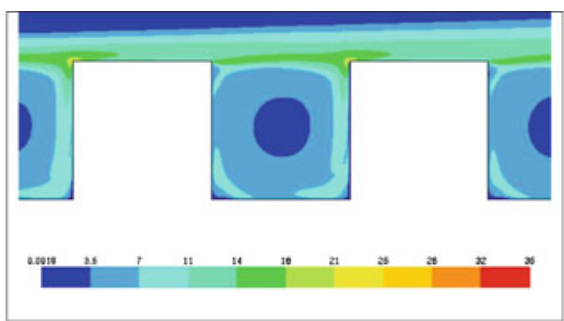

(c)

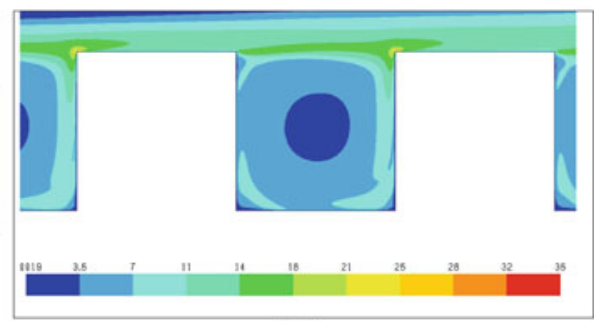

(d)

Fig. 5 Contours of turbulence intensity for the standard case of different heating situations. a Uniform-surface heating. b Ground heating. c Windward-wall heating. d Lee-ward wall heating

heat has to be carried all around the street canyon that results in accumulation of heat on the opposite side (leeward wall) and ground. Conversely, turbulence intensity is the highest at the roof level and adjacent with the windward wall (Fig. 5a). However, turbulence intensity is lower in the middle of the street canyon and close to the ground.

Further analysis is carried out with the average (area-weighted) normalized temperature along the spatial axis of the target street canyon (Fig. 6). The nodal values of temperature 


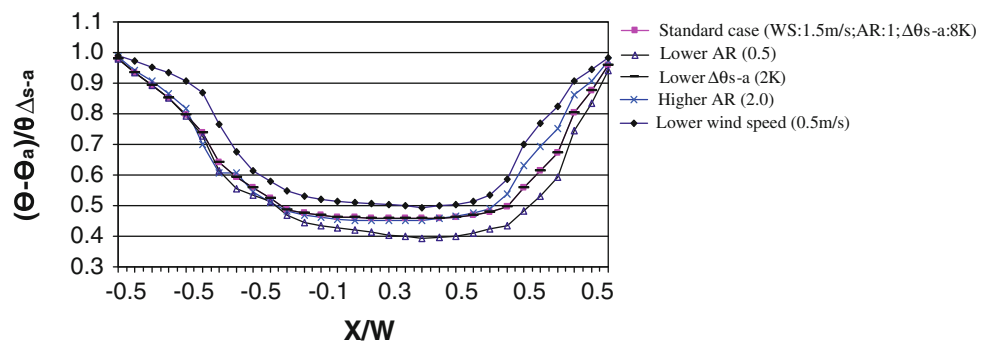

(a)

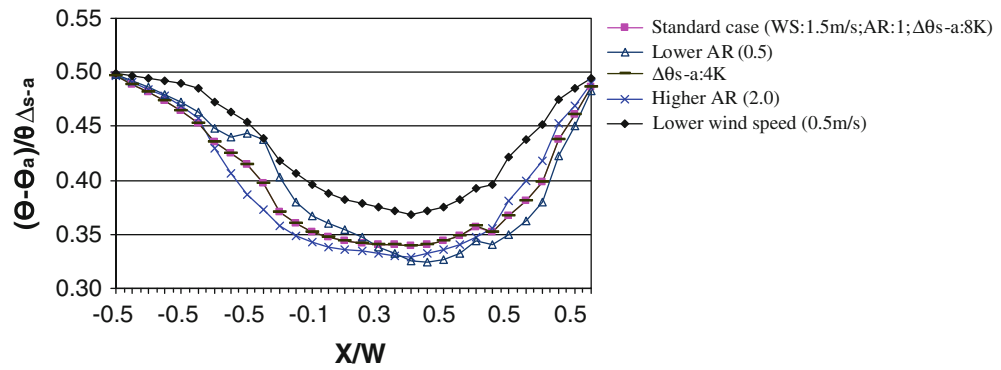

(b)

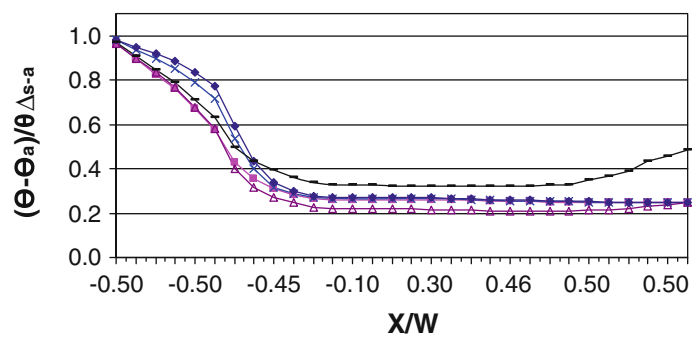

- Standard case (WS: $1.5 \mathrm{~m} / \mathrm{s} ; \mathrm{AR}: 1 ; \Delta \theta \mathrm{s}-\mathrm{a}: 8 \mathrm{~K}$ ) $\triangle \quad$ Lower AR $(0.5)$ - $\Delta \theta \mathrm{s}-\mathrm{a}: 4 \mathrm{~K}$ * Higher AR $(2.0)$ - Lower wind speed $(0.5 \mathrm{~m} / \mathrm{s})$

(c)

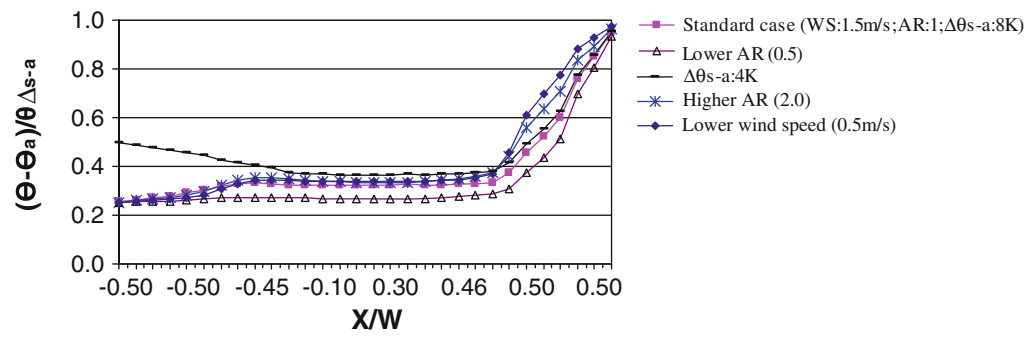

(d)

Fig. 6 Average (area-weighted) normalized air-temperatures along spatial axis of the target (middle) street canyon. Note that different simulation cases are identified with the values different that those for the standard case. a Uniform-surface heating. b Ground heating. c Leeward wall heating. d Windward wall heating

along the vertical axis (from ground up-to roof level) were averaged on the selected points of the spatial axis to obtain data for this figure. Evidently, Fig. 6a shows that air-temperatures are higher across the canyon when ambient wind speed is low (i.e., $0.5 \mathrm{~m} / \mathrm{s}$ ). Seemingly, the 'low wind speed' which causes 'poor canyon-ventilation' results in higher temperatures. It can 


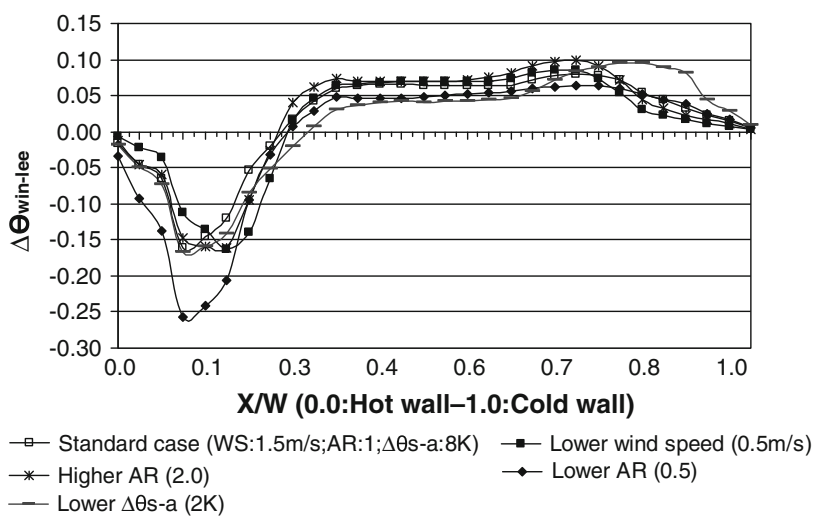

Fig. 7 Average (area-weighted) normalized temperature difference between windward and leeward wall within the target street canyon. The normalized temperatures obtained from the leeward wall heating situation were subtracted from that of windward wall heating. The first point on the spatial axis (i.e., 0.0) represents the temperature on the hotter side while the last point (i.e., 1.0) represents the temperature on the cooler wall. Note that different simulation cases are identified with the values different that those for the standard case

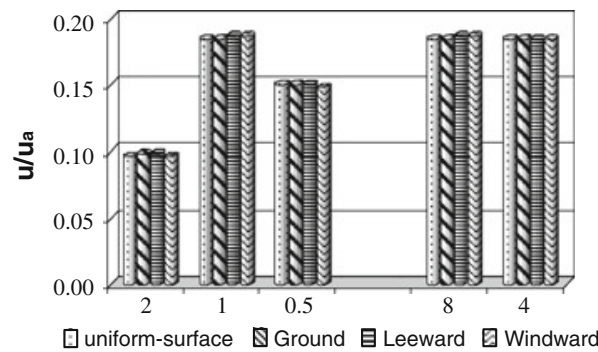

(a)

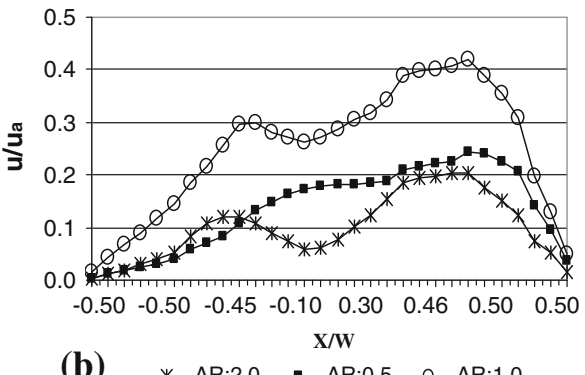

(b)

Fig. 8 Normalized velocity magnitude trends within the target street canyon (a). Whole-canyon-areaweighted-average (b). Area-weighted-average along spatial axis

also be seen that air-temperatures are higher in AR2 as compared to that in AR0.5 in particular adjacent to the windward wall. Although these higher air-temperatures might have been caused by higher heat flux due to 'larger wall surface area', however, higher air-temperatures along the windward side advocate that there has also been an impact of "poor canyon-ventilation'. Moreover, the highest velocity magnitude on the windward side is around $40 \%$ higher than that on the leeward side for the standard case (Fig. 8b). The results with a change in $\Delta \theta_{\mathrm{s}-\mathrm{a}}$ (i.e., 2 and $4 \mathrm{~K}$ ) do not demonstrate any notable difference.

\subsection{Ground heating}

Figure $4 \mathrm{~b}$ shows that a tiny portion of higher temperature is only witnessed with the corner of the leeward side. However, a contour of less higher temperature can also be seen along the leeward wall. Conversely, the temperature near the corner of leeward and windward walls is higher although the temperature with the leeward wall corner is comparatively higher. Seemingly, the intensity of the temperature reduces but the trend remained the same as that observed in the even heating of surfaces (Sect. 6.1). Conversely, the distribution of turbulence 
intensity is also similar to that observed for even heating of surfaces (Fig. 5a, b). Apparently, 'strong inflow of wind from the windward side' reduced the ground heat but its effect mitigated as it approaches to the leeward side; hence the heat accumulates along the leeward wall.

The average (area-weighted) normalized temperature along the spatial axis of the target street canyon shows further details of the above trend. Clearly, the 'poor canyon-ventilation' caused by the low ambient wind speed (i.e., $0.5 \mathrm{~m} / \mathrm{s}$ ) appears to be the main reason of heating as higher air-temperatures are evident across the canyon (Fig. 6b). The impact of building $\mathrm{AR}$ is very interesting as air-temperatures are higher along the windward wall in AR2 and along the leeward wall in AR0.5. However, average (whole-canyon-area-weighted) air-temperature in the target street canyon of AR2 was lower than that in AR0.5 (Fig. 3a). Although the aforementioned result has been reported before [6], the result is thoroughly elaborated in this paper. Clearly, air-temperatures are higher along the windward wall in AR2 which seems to be a result of 'poor canyon-ventilation' as noted under even heating of surfaces (Sect. 6.1). On the other hand, air would exchange heat with larger surface area of low temperature walls (i.e., windward and leeward walls) in AR2 as compared to that in AR0.5. Seemingly, this causes lower air-temperature along the leeward wall of AR2 as compared to that in AR0.5. Notably, a change in $\Delta \theta_{\mathrm{s}-\mathrm{a}}$ (i.e., 4 and $8 \mathrm{~K}$ ) does not demonstrate any significant impact on temperature trends during ground heating.

\subsection{Leeward/Windward wall heating}

Spatial isotherms show a tiny portion of higher temperature near the corner of the windward wall along with a contour of comparatively higher temperature with the ground in the case of windward wall heating (Fig. 4c, d). On the other hand, in the case of leeward wall heating, temperature seems to be lower throughout the street canyon except near the upper corner of the leeward wall. Seemingly, the canyon-ventilation would be poor in the case of windward wall heating as the air that enters from the windward side and exits from the leeward side could not carry heat all along the canyon. On the other hand, 'canyon-ventilation' would be better as the air flow has to remove higher temperature near its exit point in the case of leeward wall heating. The turbulence intensity distribution is almost the same for both the windward and leeward wall heating cases. Seemingly, the turbulence intensity would be higher in the wall heating cases than that for the even surface or ground heating situations as the turbulence intensity range reaches $35 \%$ in the former cases (Fig. 5). The contours for turbulence intensity seem to be similar for even surface and ground heating and for windward and leeward wall heating situations. Seemingly, turbulence intensity is influenced by the ground temperature which was the same for the cases of even surface and ground heating and for windward and leeward wall heating.

Figure $6 \mathrm{c}$ and $\mathrm{d}$ shows that air-temperatures are higher adjacent to the hotter wall and when ambient wind speed is low (i.e., $0.5 \mathrm{~m} / \mathrm{s}$ ) or AR is high (i.e., AR2). However, a sudden drop in the temperature could easily be observed due to the presence of opposite cooler wall. In the case of lower AR (i.e., AR0.5), air-temperatures are the lowest across the street canyon. Seemingly, low heat input due to 'low-wall-surface-area' and 'better-canyon-ventilation' has created this trend. The results for lower $\Delta \theta_{\mathrm{s}-\mathrm{a}}($ i.e., $4 \mathrm{~K}$ ) demonstrated higher air-temperatures throughout the street canyon as compared to those observed in the case of higher $\Delta \theta_{\mathrm{s}-\mathrm{a}}$ (i.e., $8 \mathrm{~K}$ ) except near the hotter wall. Although the resultant average temperature was higher with $\Delta \theta_{\mathrm{s}-\mathrm{a}}=8 \mathrm{~K}$; however, the normalized temperature is lower. Notably, the temperature difference between the windward and leeward walls in the case $\Delta \theta_{\mathrm{s}-\mathrm{a}}=8 \mathrm{~K}$ is higher $(6 \mathrm{~K})$ than 
that when $\Delta \theta_{\mathrm{s}-\mathrm{a}}=4 \mathrm{~K}(2 \mathrm{~K})$. Therefore, with a comparatively low temperature gradient the air-temperature does not drop significantly away from the hotter wall when $\Delta \theta_{\mathrm{s}-\mathrm{a}}=4 \mathrm{~K}$.

Figure 3 shows that average (whole-canyon-area-weighted) air-temperatures are higher when the windward wall is heated. However, air-temperatures along the windward wall were lower (refer to ground and even heating of surfaces). To elaborate these two results, air-temperature difference between windward and leeward walls $\left(\Delta \theta_{\text {win-lee }}\right)$ is depicted for different simulated cases (Fig. 7). Clearly, the $\Delta \theta_{\text {win-lee }}$ is negative near the hotter side but positive within the rest of the street canyon (i.e., away from the hotter wall). Apparently, 'better canyon-ventilation' due to strong 'inflow of wind from windward side' results in lower temperatures along the hotter wall (windward wall) during windward wall heating. However, the heat carried by the wind accumulates within the rest of the canyon. However, the effect of canyon-ventilation has been limited to only a small area near the hotter wall due to higher heat flux on the windward side. On the other hand, with lower temperatures on the windward side, during leeward wall heating, the effect of better canyon-ventilation covers the cooler side (windward wall) and larger area of the street canyon. Consequently, average air-temperatures during windward wall heating situation are higher than those during the leeward wall heating.

\subsection{Impact on ambient in-canyon wind speed}

Assessment of the impact of building AR and $\Delta \theta_{\mathrm{s}-\mathrm{a}}$ on ambient wind speed has been carried out by showing average (whole-canyon-area-weighted) velocity magnitude for the target street canyon (Fig. 8a) and average (area-weighted) velocity magnitude for the node values, from ground up-to roof level, on the selected points along spatial axis (Fig. 8b). Results for velocity magnitude shows that the ambient wind speed $(1.5 \mathrm{~m} / \mathrm{s})$ is reduced by over $90 \%$ $(1.4 \mathrm{~m} / \mathrm{s}), 84 \%(1.3 \mathrm{~m} / \mathrm{s})$ and $81 \%(1.2 \mathrm{~m} / \mathrm{s})$ in AR2.0, AR0.5 and AR1.0 street canyons, respectively. Evidently, a change in $\Delta \theta_{\mathrm{s}-\mathrm{a}}$ has no impact on ambient wind speed for the same AR. Seemingly, the flow patterns have been developed due to the specific geometries that have been formed by the changed aspect ratios. Although there has been a slight surge between AR0.5 and AR1.0, velocity magnitude has been dropped significantly between AR1 and AR2. Subsequently, velocity curve in AR1 and AR2 street canyons appears to be different from that in AR0.5 (Fig. 8b). The velocity magnitude in AR0.5 is the lowest at the leeward side and reaches the peak near windward side. On the other hand, velocity magnitude in AR1 and AR2 is higher on the leeward side dipped around the middle of the canyon and raised again.

\section{Summary}

This study aims to look into the effects of wind speed, building aspect ratio and surface and air temperature difference on the heating within street canyon. The $k-\varepsilon$ turbulence model was adopted with Renormalization Group (RNG) closure scheme to solve the Reynolds-averaged Navier-Stokes (RANS) equations. Notably, average (whole-canyon-area-weighted) temperature in AR2 street canyon is around $0.6 \mathrm{~K}(0.2 \%)$ higher than that in AR0.5. However, higher temperatures were observed with the leeward side of the canyon. Apparently, strong inflow of wind from windward side causes low temperatures on that side while heat accumulates on the leeward side of the street canyon. Seemingly, poor 'canyon-ventilation' is the main reason of higher temperatures on the leeward side as air-temperature increases with 
a decrease in ambient wind speed. Notably, the velocity magnitude on the windward side was around $40 \%$ higher than that on the leeward side for the standard case. Apparently, the temperature distribution is highly influenced by the wind direction. Conversely, the average (whole-canyon-area-weighted) air-temperature was higher in the windward wall heating situation than that during leeward wall heating. However, the temperature trends for the two situations show that the temperatures are lower along the hotter (windward) side but higher within the street canyon in the case windward wall is heated. Additionally, notable impact of a change in $\Delta \theta_{\mathrm{s}-\mathrm{a}}$ was only noticed during windward and leeward wall heating situations. Results show that ambient wind speed has reduced significantly as it flows over high aspect ratio street canyons.

A major difference in the present study and our previous published work [6] is that the air and surface temperature difference $\left(\Delta \theta_{\mathrm{s}-\mathrm{a}}\right)$ range is $8 \mathrm{~K}$ in the present study instead of $16 \mathrm{~K}$. Results show that with this comparatively lower $\Delta \theta_{\mathrm{s}-\mathrm{a}}$, the cooling requirement will be higher when the windward wall is heated i.e., during day-time. Seemingly, the tropical areas with lower $\Delta \theta_{\mathrm{s}-\mathrm{a}}$ would be observing increased cooling energy demand in summer when the windward wall is heated. Clearly, the windward wall side witnesses low temperatures during most of the situations. It is recommended that pedestrian pathways may be located on the windward side of the street canyon in tropical areas. Moreover, it is suggested that in tropical environments the leeward side of a building may be used as storage area or for a purpose that does not require much air-conditioning. On the other hand, the areas with cold environment may consider building residential housings on the leeward side of street canyon to reduce heating energy requirement for buildings.

Acknowledgements The authors are grateful to the University Research Committee, University of Hong Kong, for providing necessary funding for this work. The first author is also thankful to the Department of Mechanical Engineering, Mehran University of Engineering and Technology (MUET), Jamshoro, Pakistan for providing necessary facilities to carry out this work.

Open Access This article is distributed under the terms of the Creative Commons Attribution Noncommercial License which permits any noncommercial use, distribution, and reproduction in any medium, provided the original author(s) and source are credited.

\section{References}

1. Klysik K, Fortuniak K (1999) Temporal and spatial characteristics of the urban heat island of Lodz, Poland. Atmos Environ 33:3885-3895

2. Lemonsu A, Masson V (2002) Simulation of a summer urban breeze over Paris. Boundary-Layer Meteorol 104:463-490

3. Memon RA, Leung DYC, Liu CH (2009) An investigation of urban heat island intensity (UHII) as an indicator of urban heating. Atmos Res 94:491-500

4. Hafner J, Kidder SQ (1999) Urban Heat Island modeling in conjunction with satellite-derived surface / soil parameters. J Appl Meteorol 38:448-465

5. Memon RA, Leung DYC, Liu CH (2008) A review on the generation, determination and mitigation of urban heat island. J Environ Sci 20:120-128

6. Memon RA, Leung DYC, Liu CH (2010) Effects of building aspect ratio and wind speed on air-temperatures in urban-like street canyons. Build Environ 45:176-188

7. Ashie Y, Thanh VC, Asaeda T (1999) Building canopy model for the analysis of urban climate. J Wind Eng Ind Aerodyn 81:237-248

8. Masson V (2000) A physically based scheme for the urban energy budget in atmospheric models. Boundary-Layer Meteorol 94:357-397

9. Yamada T (2000) Building and terrain effects in a mesoscale model. In: 11th conference on air pollution meteorology, Long Beach California, New Mexico, January 9-14, pp 215-220 
10. Masson V, Grimmond CSB, Oke TR (2002) Evaluation of the town energy balance (TEB) scheme with direct measurements from dry districts in two cities. J Appl Meteorol 41:1011-1026

11. Takahashi K, Yoshida H, Tanaka Y, Aotake N, Wang F (2004) Measurement of thermal environment in Kyoto city and its prediction by CFD simulation. Energy Build 36:771-779

12. Dupont S, Otte T, Ching JKS (2004) Simulation of Meteorological fields within and above urban and rural canopies with a mesoscale model (MM5). Boundary-Layer Meteorol 113:111-158

13. Huang H, Ooka R, Kato S (2005) Urban thermal environment measurements and numerical simulation for an actual complex urban area covering a large district heating and cooling system in summer. Atmos Environ 39:6362-6375

14. Kato S, Yamaguchi Y (2005) Analysis of urban heat island effect using ASTER and ETM+ data: separation of anthropogenic heat discharge and natural heat radiation from sensible heat flux. Remote Sens Environ 99:45-54

15. Arnfield AJ, Grimmond CSB (1998) An urban canyon energy budget model and its application to urban storage heat flux modeling. Energy Build 27:61-68

16. Atkinson BW (2003) Numerical modeling of urban heat island intensity. Boundary-Layer Meteorol 109:285-310

17. Xia JY, Leung DYC (2001) Pollutant dispersion in urban street canopies. Atmos Environ 35:2033-2043

18. Li X, Liu CH, Leung DYC (2005) Development of a k- $\varepsilon$ model for the determination of air exchange rates for the street canyons. Atmos Environ 39:7285-7296

19. Liu CH, Leung DYC, Barth MC (2005) On the prediction of air and pollutant exchange rates in street canyons of different aspect ratios using large-eddy simulation. Atmos Environ 39:1567-1574

20. Eliasson I, Offerle B (2006) Wind fields and turbulence statistics in an urban street canyon. Atmos Environ 40:1-16

21. Xie X, Huang Z, Wang JS (2006) The impact of urban street layout on local atmospheric environment. Build Environ 41:1352-1363

22. Sini JF, Anquetin S, Mestayer PG (1996) Pollution dispersion and thermal effects in urban street canyon. Atmos Environ 30:2659-2677

23. Kim JJ, Baik JJ (2001) Urban street-canyon flows with bottom heating. Atmos Environ 35:3395-3404

24. Xie X, Huang Z, Wang JS, Xie Z (2005) The impact of solar radiation and street layout on pollutant dispersion in street canyon. Build Environ 40:201-212

25. Xie X, Liu CH, Leung DYC, Leung MKH (2006) Characteristics of air exchange in a street canyon with ground heating. Atmos Environ 40:6396-6409

26. Xie X, Liu CH, Leung DYC, Leung MKH (2007) Impact of building facades and ground heating on wind flow and pollutant transport in street canyons. Atmos Environ 41:9030-9049

27. Chan TL, Dong G, Leung CW, Cheung CS, Hung WT (2002) Validation of a two-dimensional pollutant dispersion model in an isolated street canyon. Atmos Environ 36:72-861

28. Yakhot V, Orszag SA (1986) Renormalization group analysis of turbulence. J Sci Comput 1:1-51

29. Fluent User Guide version 6.2.1, 2005

30. Jongen T (1992) Simulation and modeling of turbulent incompressible flows. PhD thesis, EPF Lausanne, Lausanne, Switzerland

31. Wolfstein M (1969) The velocity and temperature distribution of one-dimensional flow with turbulence augmentation and pressure gradient. Int J Heat Mass Transf 12:301-318

32. Uehara K, Murakami S, Oikawa S, Wakamatsu S (2000) Wind tunnel experiments on how thermal stratification affects flow in and above urban street canyons. Atmos Environ 34:1553-1562

33. Sabatino D, Buccolieri R, Pulvirenti B, Britter R (2007) Application and validation of FLUENT flow and dispersion modeling within complex geometries. Dev Environ Sci 6:3-11 